\title{
Experimental Investigation of Oligo Cyclic Compression Behavior of Pure Epoxy and Graphene-Epoxy Nanocomposites
}

\author{
Ozgen U. Colak ${ }^{\mathrm{a}, \mathrm{c}}$, Deniz Uzunsoy ${ }^{\mathrm{b}}$, Nadia Bahlouli $^{\mathrm{c}}$, and Charles Francart ${ }^{\mathrm{c}}$
}

\begin{abstract}
${ }^{a} Y 11$ 1z Technical University, Department of Mechanical Engineering, Istanbul, Turkey
${ }^{b}$ Bursa Technical University, Department of Metallurgy \& Materials Engineering, Turkey 'ICube Laboratory, UMR 7357 CNRS, Department of Mechanics, University of Strasbourg, Strasbourg, France
\end{abstract}

\author{
ozgen@yildiz.edu.tr, deniz.uzunsoy@btu.edu.tr, \\ nadia.bahlouli@unistra.fr, cfrancart@unistra.fr
}

\begin{abstract}
The loading-unloading compression behavior and the oligo cyclic behavior of pure epoxy and graphene-epoxy nanocomposites are investigated since the systematic evaluation of the mechanical behavior under cyclic loading is of great importance in the development of damage characterization and fatigue models for polymer composites. High purity graphene nanoflakes (GNF) are synthesized by electric arc discharge method and the manufacturing of graphene epoxy nanocomposites is done using solution blending. The structural characterizations of produced GNF are performed using several techniques such as transmission electron microscopy (TEM), Raman spectroscopy, Brunauer-Emmett-Teller (BET). Oligo quasi static strain controlled cyclic tests are performed at the elastic (or viscoelastic) region, around yield and after softening at the viscoplastic region. Comparing the behavior under compression loading-unloading and oligo (repeated) cycled reveals that prehistory does not have much effect on the subsequent behavior. The change in the elasticity modulus during repeated cyclic compression is determined. It is observed that elasticity modulus decreases initially, then it progressively increases with the increase of applied maximum strain. Compared to epoxy, the yield stresses of graphene-epoxy decrease in both strain rates and a small increase in the elasticity modulus of graphene-epoxy is observed at low strain rate (1.E-4/s).
\end{abstract}

Corresponding Author: Ozgen U. Colak, e-mail: ozgen@yildiz.edu.tr

Keywords: oligo cyclic, graphene-epoxy, viscoplasticity, graphene 


\section{Introduction}

Increasing trends in the application of polymeric materials and polymer matrix composites in many industries, from aerospace to automotive, leads to the requirement of investigation of mechanical properties under different loading conditions. Polymers are reinforced by various sized fillers to improve properties. Among these fillers, graphene, single layer of carbon atoms, has got much attention since the physics Nobel Prize in 2010 given to Geim and Novoselov for graphene synthesis, [1]. Graphene as a versatile nanosheet material can be utilized in numerous fields including composite materials, bioengineering, energy technologies, electronics etc. The properties of graphene such as exceptional electron transport capacity, superior mechanical strength and high surface area, have lead researchers to develop nanocomposite polymeric membranes containing graphene. It is an effective nanosheet filler for separation applications. Recent trends for developing nanocomposite membranes prepared by incorporating nanofillers into a polymer matrix seem to offer improved physical, chemical and separation properties [2]. Due to high thermal conductivity and high aspect ratio, graphene can be utilized effectively as a thermally conductive filler in thermal interface materials. Because of its high electrical conductivity, graphene cannot be used when electric insulation is required. To overcome these drawbacks, a small amount of alumina-coated graphene improved the thermal conductivity of the alumina sphere/ thermoplastic polyurethane (TPU) composite without any increase in the electrical conductivity [3]. Another interesting application areas of graphene is biomedical. It is useful in the detection and treatment of diseases and transport specific drugs to the target organs [4].

Even though graphene has extra ordinary properties [5], when it is used as reinforcement in the polymer matrix, the resulting nanocomposite does not have expected high mechanical properties. Several parameters affect the mechanical properties of graphene-based nanocomposites such as the structure of the graphene, the preparation method, the dispersion of the filler in the matrix, the filler matrix interactions and the orientation of the filler, [5]. Some of the works about graphene reinforced nanocomposites reveal increases in the mechanical properties such as elasticity modulus and ultimate strength, $[5,6]$ but, some of them reveal decreases in the ultimate tensile strength which is highly affected by aggregation of the filler $[7,8]$. To achieve high performance polymer nanocomposites, dispersion of nanofillers in polymers is critical. Generally, three major methods are available for good dispersion. The first is direct mixing of nanoparticles, the second is in situ polymerization in the presence of nanoparticles. The third one is combination of both in situ formation of the nanoparticles and 
in situ polymerization, [9]. Proper selection of fabrication process of nanocomposites requires to obtain polymer matrix nanocomposites with high mechanical properties.

Recent researches on the graphene-epoxy nanocomposites have focused on fabrication and characterization at quasi-static loadings [10-16]. Various attempts to characterize the nonlinear response are done, however, these studies are mainly limited to monotonic loading $[6,7,8,13$, 14, 15]. For example, in the work by Topal et al. [14], the reinforcing effects of GNP and reduced graphene oxide (RGO) on epoxy resin are examined by tensile testing and dynamic mechanical analysis (DMA). The decrease in the ultimate tensile strength, an improvement in the elasticity modulus have been observed. In the work by Shadlou et al. [15], the influences of strain rate on the mechanical behavior of epoxy reinforced with graphene nanoplatelets (GNPs) is investigated under quasi static compressive and tensile loadings.

Some of the works about cyclic behavior of polymers and composites can be mentioned as follow: A series of monotonic and cyclic loading-unloading compression tests are carried out by Zhai et al. [17] on quasi-unidirectional E-glass fabric reinforced polypropylene composites. Both irreversible strains and stiffness degradation are observed in cyclic loading-unloading tests, which indicate that the nonlinear response of nanocomposites is induced by a combination of damage and plasticity, [17]. Five cycles of compressive loading and unloading tests are carried out with a gradually increasing peak stress by Wang et al. [18]. The material that they investigated is unidirectional HTS40/PA6 carbon/polyamide laminates. Chen et al. [19], studied the damage evolution of a polymer-bonded explosive (PBX) substitute material under monotonic and repeated compression tests. It is observed that the damage parameter increases with the increasing applied strain. The damage evolution is described by damage parameter D as a function of applied strain, [19].

In the work by Ayoub et al. [20], uniaxial stress-strain behavior of HDPE is investigated by performing monotonic loading and unloading and reloading tests. The elasticity modulus is determined using the unloading curves. It is observed that elastic stiffness significantly depends on the strain level during unloading. Initially, a decrease in the elasticity modulus, then an increase is observed. Decrease in the elasticity modulus is associated to a considerable decrease of the viscoelasticity with plastic strain and to structural damage which takes place during cyclic loading. It can correspond to the progressive fragmentation of crystallites and the microcavitation at the spherulite nuclei. The increase of the elasticity modulus is linked to the highly anisotropic plastic behavior that develops during the significant strain hardening, [20].

In the detailed literature review, it is seen that compression loading and unloading and also cyclic or oligo cyclic compression loading behavior of pure epoxy and graphene-epoxy 
nanocomposites are not investigated. The main uniqueness of the present work is the investigation of cyclic behavior (loading-unloading and repeated cycled compression) of GNFepoxy nanocomposite and epoxy. Since systematic evaluation of the materials under cyclic loading is of great importance in the development of damage characterization and fatigue models for polymer composites, [18], the cyclic compression behaviors (loading unloading and oligo cyclic) of epoxy and graphene-epoxy nanocomposites are investigated. The synthesis of graphene with 5, 6 layers are done using electric arc discharge method. Then, the grapheneepoxy nanocomposites are prepared by means of solution mixing. Several techniques such as transmission electron microscopy (TEM), Raman spectroscopy, Brunauer-Emmett-Teller (BET) are used for the structural characterizations of produced GNF's. For the mechanical characterization of pure epoxy and nanocomposites, compression loading unloading tests and three cycles of compressive loading and unloading tests are carried out with a gradually increasing peak stress. To investigate the viscoelastic and viscoplastic behavior, tests are performed at two different strain rates (1.E-3/s and 1.E-4/s). By measuring the slope of initial unloading curves, the change in the elasticity modulus with cycles are calculated.

\section{Experimental work}

\subsection{Materials}

Epoxy resin used in this work is based on System 2000 epoxy resin by Fibregrast Inc. (USA) and System 2120 epoxy hardener is used as curing agent. The mixing ratio of epoxy resin and hardener is 70:30 respectively, by weight, as recommended by producer. All the reagent are used as received. As solvent, acetone are used.

\subsection{Preparation of graphene nanoflakes $(G N F)$ and graphene-epoxy nanocomposite}

The method to obtain a few layered graphene is electric arc discharge. A homemade stainless steel reactor is used to synthesize graphene flakes from graphite rods. In the electric arc discharge method, the parameters such as buffer gases, pressure, current, electrode diameters affect the purity and number of layers of synthesized graphene. In the work by Topal et al. [14] and Cotul et al. [21], these parameters are optimized and the following parameters are used in the synthesis of graphene flakes, (Table 1). 
Table 1 . The parameters to obtain graphene flakes by electric arc discharge method.

\begin{tabular}{|c|c|}
\hline Electrodes & $\begin{array}{c}99,9 \% \text { purity, } \\
\end{array}$ \\
Rod diameter and length: $12 \mathrm{~mm} \times 10 \mathrm{~cm}$ \\
\hline Gases and ratio & Helium, nitrogen, $50 \%-50 \%$ \\
\hline Pressure of gas & $0.1 \mathrm{bar}$ \\
\hline Vacuum period before the synthesis & 5 min. \\
\hline Arc current during the synthesis & $150 \mathrm{~A}$ \\
\hline
\end{tabular}

Graphene-polymer nanocomposites can be prepared by means of solution mixing, in situ polymerization and melt blending. Solution mixing is the most commonly used wet chemical process for fabrication of polymer nanocomposites. Wet chemical processing offers better dispersion of nanofillers in the polymer matrix than the melt blending process. The process involves the dissolution of polymer in a suitable solvent followed by mixing with graphene under stirring or sonication. Graphene nanoflakes (GNF) is dispersed in solvent by ultrasonication for 1.5 hour by using an ultrasonic probe sonicator. Then, epoxy resin is added to the mixture and sonicated for another 1.5 h. (System 2000 Epoxy Resin by Fibregrast Inc. USA). For the case of acetone, solvent is evaporated on a magneting stir plate for 3 hours at 70 ${ }^{\circ} \mathrm{C}$. The evaporation procedure continues in a vacuum chamber for 12 hour at $70{ }^{\circ} \mathrm{C}$ for acetone. After the cooling of this mixture, a curing agent is added (2120 epoxy hardener, Fibregrast Inc.), and mixed in a vacuum mixer for 10 minutes. The mixture is placed in a vacuum chamber to degas the epoxy for approximately 30 minutes (vacuum mixer is used as the vacuum chamber). The curing is made on silicone molds at room temperature for 24 hours followed by a post cure of 4 hour at $90{ }^{\circ} \mathrm{C},[10]$.

\subsection{Characterization of GNF}

Techniques used for the structural characterizations of GNF's are transmission electron microscopy (TEM), Raman spectroscopy and Brunauer-Emmett-Teller (BET). TEM micrograph is recorded on a JEOL JEM 2100 UHR microscope equipped with an X-ray energy dispersive spectrometer operated at $200 \mathrm{kV}$ using a copper grid. For TEM study, a drop of diluted dispersion is placed on substrate and dried at ambient conditions. Raman spectroscopy (Renishaw in via reflex) is used to determine graphene's purity and number of layers. The Raman spectra is measured from 500 to $3000 \mathrm{~cm}-1$ via an excitation wavelength of $532 \mathrm{~nm}$. 
Surface area value of the powders was identified according to the Brunauer-Emmett-Teller (BET) theory in a Micrometrics ${ }^{\mathrm{TM}}$ Tristar III surface area analyzer. The degassing of sample was performed at $105{ }^{\circ} \mathrm{C}$ under $\mathrm{N}_{2}$ gas for $12 \mathrm{~h}$ and by absorbing with $\mathrm{N}_{2}$ (for analysis) and $\mathrm{He}$ (for reference) gases.

Fig.1 shows the Raman spectroscopy results of synthesized GNF, graphite electrode and commercial graphene. Table 2 also summarizes D, G and 2D bands of GNF collected near to the anode electrode in the reactor, graphite electrode and commercial graphene, respectively. $\mathrm{D}$ band indicates defects in the structure of carbon based materials due to the lattice distortion introduced by impurity elements. The position and shape of the $\mathrm{G}$ band shows doping effect, defects, number of graphene layers and stress. The 2D band is the characteristic band of graphene and its shape is related to the number of layers.

$\mathrm{I}_{\mathrm{G}} / \mathrm{I}_{2 \mathrm{D}}$ ratio is calculated with Raman spectroscopy results in order to determine the total graphene layers while, $I_{D} / I_{G}$ ratio is used to obtain information about graphene's purity. Table 1 shows $I_{D} / I_{G}$ and $I_{G} / I_{2 D}$ ratios of $G N F$, commercial graphene and graphite electrode. The $I_{D} / I_{G}$ ratios of GNF, commercial graphene and graphite electrode were calculated as 0.52, 0.68 and 0.68 , respectively. These high values of $\mathrm{I}_{\mathrm{D}} / \mathrm{I}_{\mathrm{G}}$ indicate a low crystallinity and purity $[22,23]$. The synthesized GNF has high purity and few layer structures according to the band results obtained from Raman spectroscopy. Wu et al. [24] synthesized few-layered graphene using an arc discharge method and they reported that $\mathrm{I}_{\mathrm{G}} / \mathrm{I}_{2 \mathrm{D}}$ value of approximately 0.4 corresponds to a single layer. Reina et al. [25] produced a few-layered graphene on arbitrary substrates by chemical vapor deposition and they determined $\mathrm{I}_{\mathrm{G}} / \mathrm{I}_{2} \mathrm{D}$ ratio as 1.3 corresponds to approximately three layer graphene. The $\mathrm{I}_{\mathrm{G}} / \mathrm{I}_{2} \mathrm{D}$ ratio of GNFs obtained by the electric arc discharge method has a value compatible with these graphene nano plates produced by CVD method. In addition, Paton et al. [26] synthesized single layer graphene sheets by liquid phase exfoliation method which corresponds to $\mathrm{IG}_{\mathrm{G}} / \mathrm{I}_{2 \mathrm{D}}$ ratio as 1.5 . It is seen that the $\mathrm{I}_{\mathrm{G}} / \mathrm{I}_{2 \mathrm{D}}$ ratio of commercial graphene is higher than GNF produced by electric arc discharge method.

The 2D band width of graphite electrode is found a little wider comparing to the one obtained from GNF and shifted in terms of wavenumber as shown in Fig. 1 The 2D band of graphite is strongly asymmetrical and this form of the band is used to differentiate graphene from graphite. Moreover, the form of 2D band is affected by stress and this leads to the widening effect in the peak geometry. 


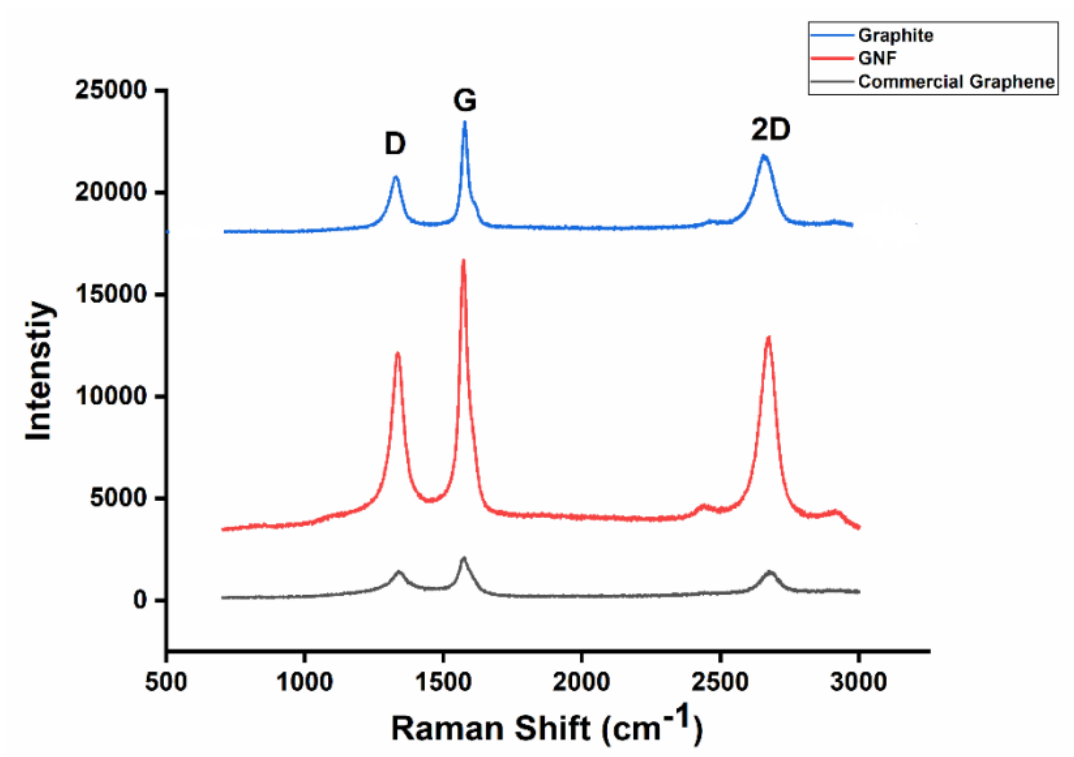

Fig. 1 Raman Spectroscopy results for GNF, graphite electrode and commercial graphene

Table 2. The intensity of band ratios for GNF and graphite electrode

\begin{tabular}{|c|c|c|c|c|c|}
\hline & $\begin{array}{c}\text { Intensity of } \\
\text { D band (ID) }\end{array}$ & $\begin{array}{c}\text { Intensity of } \\
\mathrm{G} \text { band }\left(\mathrm{I}_{\mathrm{G}}\right)\end{array}$ & $\begin{array}{c}\text { Intensity of } \\
\text { 2D band } \\
\left(\mathrm{I}_{2 \mathrm{D}}\right)\end{array}$ & $\mathrm{I}_{\mathrm{D}} / \mathrm{I}_{\mathrm{G}}$ ratio & $\mathrm{I}_{\mathrm{G}} / \mathrm{I}_{2 \mathrm{D}}$ ratio \\
\hline $\begin{array}{c}\text { Graphite } \\
\text { electrode }\end{array}$ & 2947 & 5622 & 3976 & 0.52 & 1.41 \\
\hline GNF & 10452 & 15177 & 11363 & 0.68 & 1.33 \\
\hline $\begin{array}{c}\text { Commercial } \\
\text { Graphene }\end{array}$ & 1409 & 2062 & 1400 & 0.68 & 1.47 \\
\hline
\end{tabular}

TEM image of GNF is shown in Fig. 2. The synthesized GNF shows characteristic structure of graphene having different levels of transparency with wrinkles. The number of layers can be also seen from the folded side of graphene flakes. The synthesized GNF has 2 to 10 layers, which is in good agreement with Raman analysis. 

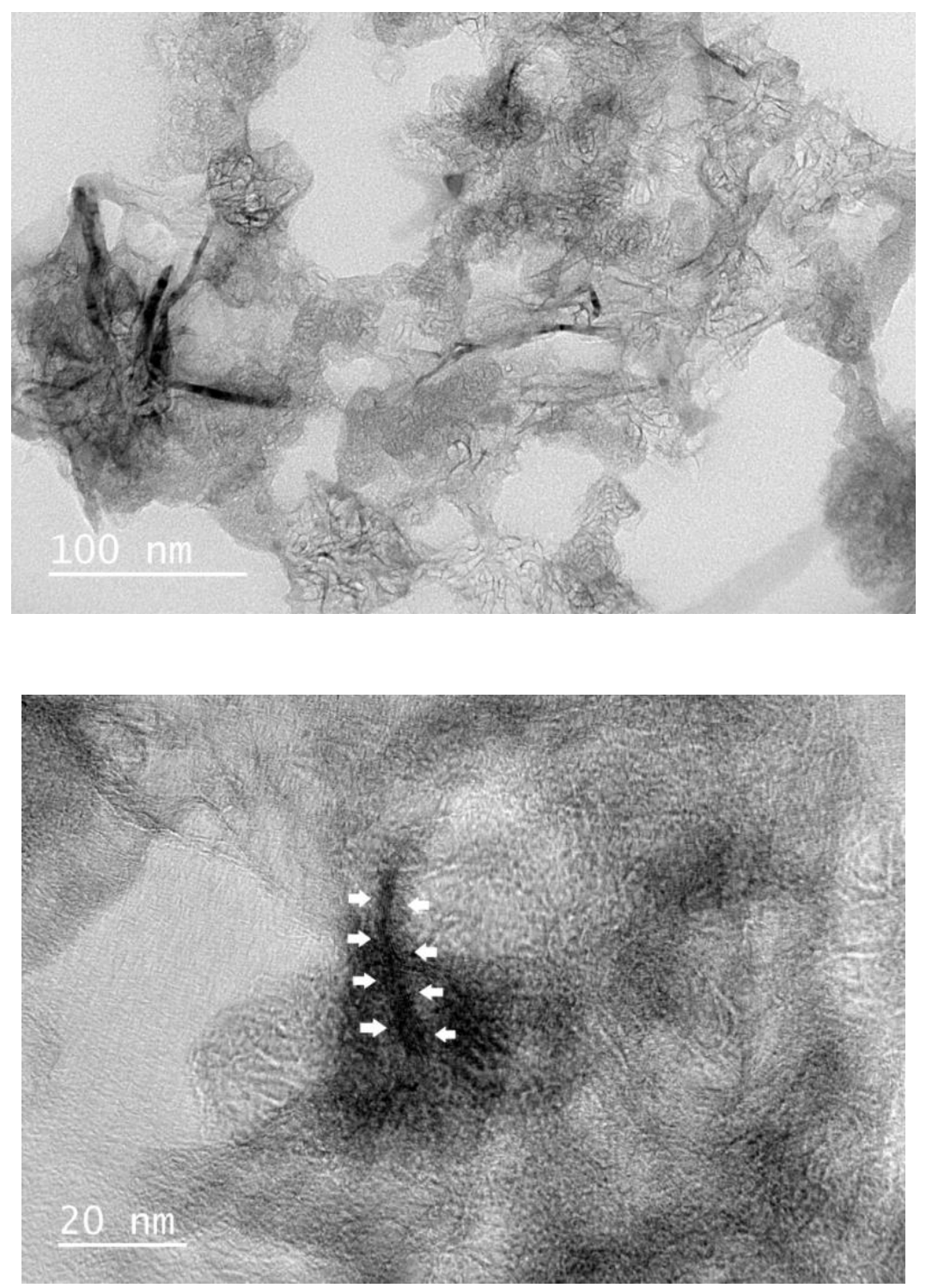

Fig. 2. TEM images of obtained GNF

BET surface area of the GNF sample is measured as $153.52 \pm 2.36 \mathrm{~m}^{2} / \mathrm{g}$. With the aim of the comparison, BET surface area of a commercial graphene (Sigma Aldrich, 25 $\mu \mathrm{m}$ ) was determined as $47.72 \pm 2.68 \mathrm{~m}^{2} / \mathrm{g}$. It is clear that these values are lower than the theoretical surface area of a single layer graphene which is $2630 \mathrm{~m}^{2} / \mathrm{g}$ [27]. This variation could be related to GNF produced by different methods. The current decrease is due to the fact that the graphene produced is a few layered [28]. The surface area is the important parameter for graphene in some applications such as polymer nanocomposites, supercapacitors, batteries, and solar cell, transistor. If graphene has a high specific surface area, the graphene platelets show a good dispersion in the matrix of the composite with low mass volume and higher electrochemically active surface [29]. 


\section{Mechanical Characterization of epoxy and graphene-epoxy nanocomposite}

\subsection{Quasi static compression tests}

Universal testing machine (INSTRON 5969) is used to perform quasi static compression tests of the pure epoxy and graphene-epoxy nanocomposite. The dimensions of the samples are $12 \mathrm{~mm}$ in diameter and $5 \mathrm{~mm}$ in thickness. Four specimens for each condition are tested and averages are taken. To investigate the influences of strain rate on the mechanical behavior, compression tests (loading and unloading) are performed at two strain rates, (1.E-3 and 1.E-4 /s). No barreling effect has been observed for all the specimen. Strain rate dependency of epoxy under compression loading and unloading is depicted in Fig. 3. The epoxy under compression loading exhibits almost a linear viscoelastic behavior. Following the yielding, small strain softening is observed and then, nonlinear hardening and nonlinear unloading. With plastic straining, hardening occurs due the entanglement of the polymer chains. Additional mechanism is activated with the increase of the strain rate. The increases in stiffness and strength with the increase of strain rate are also due to the polymer chains motions which are associated with the secondary relaxation processes [30,31]. At high strain rates, the molecular motions of the chains are restricted. Time for rearrangement of polymer chains is less during the high strain rates. Since the fundamental process of yielding of amorphous polymers consists of the jump of macromolecule segments from one equilibrium position to another [32], at a higher strain rate, there is a higher molecular resistance to jumps and, hence, a higher yield stress is observed [33].

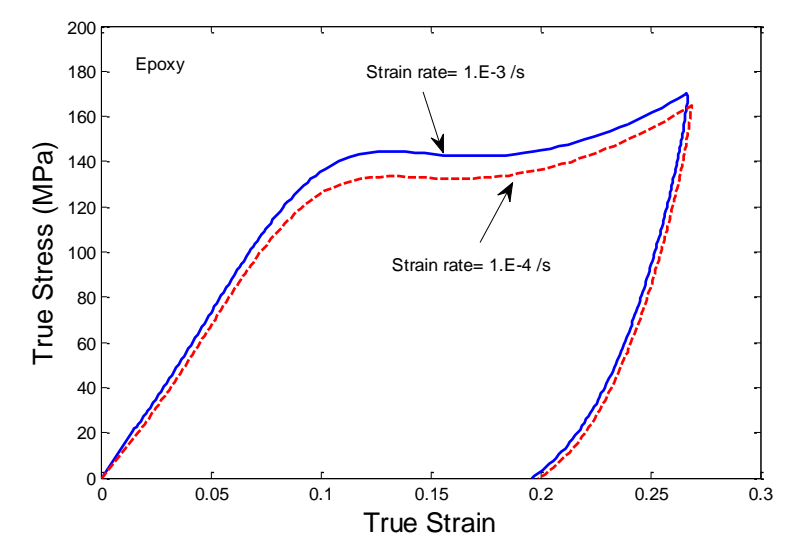

a) Epoxy

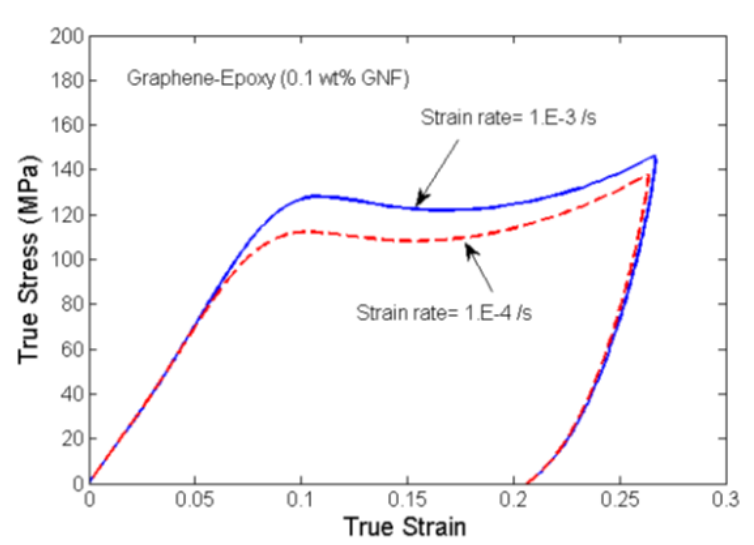

b) Graphene-epoxy (0.1 wt \% GNF)

Fig. 3. Uniaxial compression behavior of (a) epoxy and (b) graphene-epoxy (0.1 wt \% GNF) (loading-unloading behavior) at two different strain rate 
Almost rate independent behavior is observed during loading and unloading in the grapheneepoxy nanocomposite. After yielding, a slight stress softening is observed due to the decrease of the internal stress which may result in a rearrangement of molecular defects until a more stable configuration is reached [34]. This decrease in the stress, which is much more pronounced when the deformation rate is increased, probably owes its origin to the deformation mechanism, which consists of the appearance of shear bands. The shift of the shear localization process by the increase of strain rate is undoubtedly an important factor of the brittleness of the resins in the propagation of cracks. Indeed, the increase of the threshold stress with the increase of the speed delays the process of shear localization which increases the volume stress [35]. This volume release will allow the polymer chains to move more, thus reducing the level of stress (stress softening). The chains will thus be able to reorganize themselves in order to align themselves. Then the chains will stretch, which results in the observation of an increase in stress with an increase in deformation (strain hardening). The elasticity modulus and the yield stresses for both strain rate and materials are depicted in Table 3.

Table 3. The mechanical properties of epoxy and graphene-epoxy nanocomposite

\begin{tabular}{|c|c|c|c|c|}
\hline $\begin{array}{c}\text { Strain rate } \\
(/ \mathrm{s})\end{array}$ & \multicolumn{2}{|c|}{ Epoxy } & \multicolumn{2}{c|}{ Graphene- Epoxy (0.1 wt\% GNF) } \\
\hline & $\begin{array}{c}\text { Elasticity } \\
\text { modulus (MPa) }\end{array}$ & Yield stress (MPa) & $\begin{array}{c}\text { Elasticity } \\
\text { modulus (MPa) }\end{array}$ & $\begin{array}{c}\text { Yield stress } \\
(\mathrm{MPa})\end{array}$ \\
\hline $1 . \mathrm{E}-3$ & $1422 \pm 16$ & $144.4 \pm 0.6$ & $1388 \pm 22$ & $128.05 \pm 0.04$ \\
\hline $1 . \mathrm{E}-4$ & $1365 \pm 49$ & $132.3 \pm 1.3$ & $1399 \pm 39$ & $110.96 \pm 2.1$ \\
\hline
\end{tabular}

\subsection{Quasi static strain controlled oligo cyclic compression tests}

Three cycles of compressive oligo cyclic loading and unloading tests are carried out with a gradually increasing peak stress. The number of cycles is selected as three in order to stay in a domain where low-cycle fatigue phenomena can be negligible [17]. The strain levels in each cycle is selected in such a way that the behaviors in elastic region (or viscoelastic), around yield and viscoplastic region can be investigated. Therefore, quasi static strain controlled cyclic tests are performed at elastic region, around yield and after softening at viscoplastic region.

\subsubsection{Pure epoxy oligo cyclic compression tests}

The results of three cycles of compressive loading and unloading tests for epoxy are depicted in Fig. 4 for two different strain rates (1.E-3/s and 1-E-4/s). 


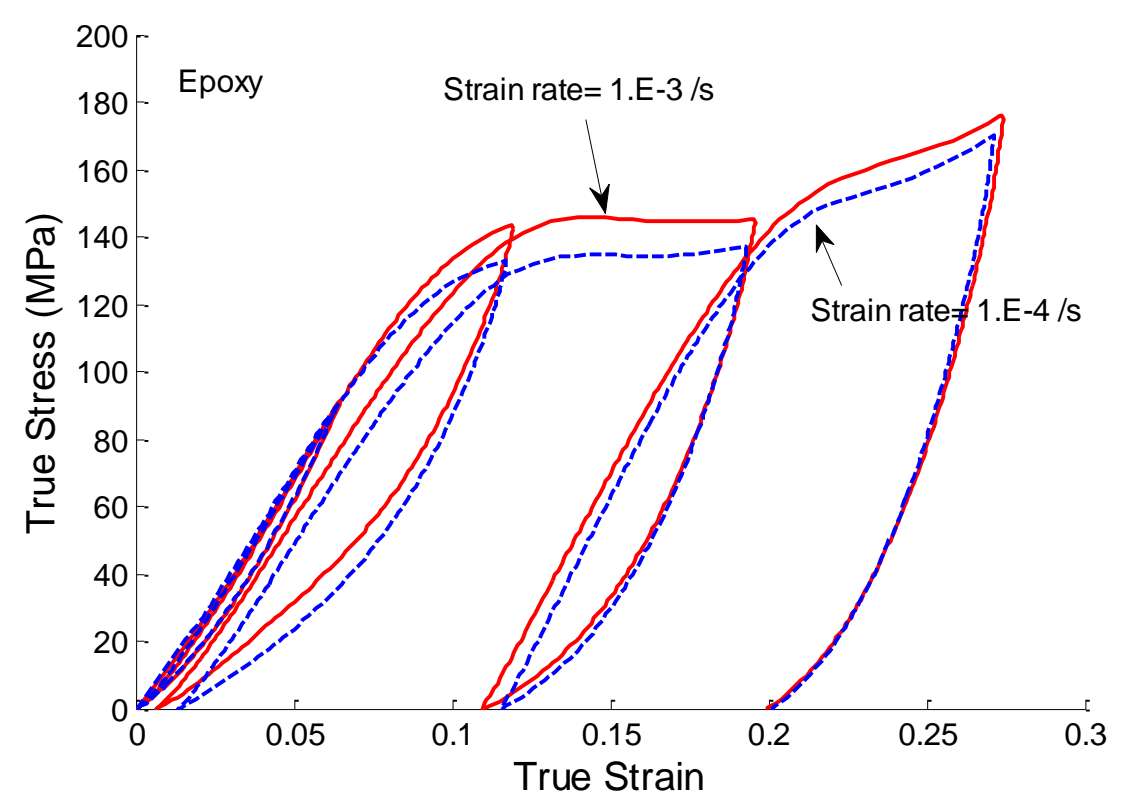

Fig. 4. Rate dependent oligo cyclic behavior of epoxy.

Fig. 4 exhibits the stress-strain curves at two different strain rate under oligo cyclic compression tests. Due to the viscoelastic properties of the matrix materials, the nonlinear stress-strain behaviors are observed in the nanocomposites. Following the first loading and unloading cycle, each subsequent one begins at the residual strain left from the previous one. The first cycle is performed at viscoelastic region at around 0.06 strain level and a hysteresis loop is observed without residual strain. In the subsequent cycles which are at 0.11, 0.19 and last unloading around 0.27 strain level, viscoplastic strain are left after each unloading.

The aim of repeated cyclic loading is to investigate the change in the modulus (elasticity) and linked it to the mechanisms which will be used in the modeling in future works. The analysis of the change in the modulus will also help to understand the material failure mechanism and its modelling. The elasticity modulus measured from the slope of initial reloading curves are depicted in Table 4.

Table 4. The oligo cyclic compression properties of epoxy

\begin{tabular}{|l|l|l|l|l|}
\hline $\begin{array}{l}\text { Strain rate } \\
(/ \mathrm{s})\end{array}$ & $\begin{array}{l}\text { Elasticity modulus } \\
(\mathrm{MPa}) \\
\text { Initial loading }\end{array}$ & $\begin{array}{l}\text { Elasticity } \\
\text { modulus }(\mathrm{MPa}) \\
1 . \text { cycle }\end{array}$ & $\begin{array}{l}\text { Elasticity } \\
\text { modulus }(\mathrm{MPa}) \\
2 . \text { cycle }\end{array}$ & $\begin{array}{l}\text { Elasticity } \\
\text { modulus }(\mathrm{MPa}) \\
3 . \text { cycle }\end{array}$ \\
\hline $1 . \mathrm{E}-3$ & $1351 \pm 7$ & $1311 \pm 13$ & $1338 \pm 1$ & $1749 \pm 23$ \\
\hline $1 . \mathrm{E}-4$ & $1357 \pm 28$ & $1317 \pm 28$ & $1342 \pm 12$ & $1805 \pm 25$ \\
\hline
\end{tabular}


As seen from Table 4, the elasticity modulus is decreased in the first cycle which is performed in elastic region well below the yield stress. When the modulus in the first cycle is compared to the modulus in second cycle (unloading just after yield and reloading), it is seen that modulus is increased for both strain rate cases. When cyclic loading is continued, after softening behavior (end of softening, starting of hardening behavior), the elasticity modulus continues to increase.

It is also observed that only the first cycle does not cause any residual deformation. From the second cycle onwards, a residual deformation is obtained and given in Table 5. This residual deformation increases with each cycle. The deformation after each unloading is not tracked to measure the relaxation of the material. That was not the purpose of this paper.

Table 5. Plastic strains of epoxy at the end of the each cycle

\begin{tabular}{|l|l|l|l|l|}
\hline $\begin{array}{l}\text { Strain rate } \\
(/ \mathrm{s})\end{array}$ & $\begin{array}{l}\text { Plastic strain at the } \\
\text { end of } \\
1 . \text { cycle }\end{array}$ & $\begin{array}{l}\text { Plastic strain at the } \\
\text { end of } \\
2 . \text { cycle }\end{array}$ & $\begin{array}{l}\text { Plastic strain at } \\
\text { the end of } \\
\text { 3. cycle }\end{array}$ & $\begin{array}{l}\text { Plastic strain at } \\
\text { the end of } \\
\text { 4. cycle }\end{array}$ \\
\hline $1 . \mathrm{E}-3$ & 0.016 & 0.008 & 0.1 & 0.2 \\
\hline $1 . \mathrm{E}-4$ & 0 & 0.013 & 0.115 & 0.2 \\
\hline
\end{tabular}

The comparison of stress-strain behavior during compression loading-unloading and oligo cycle compression test results is depicted in Fig. 5.

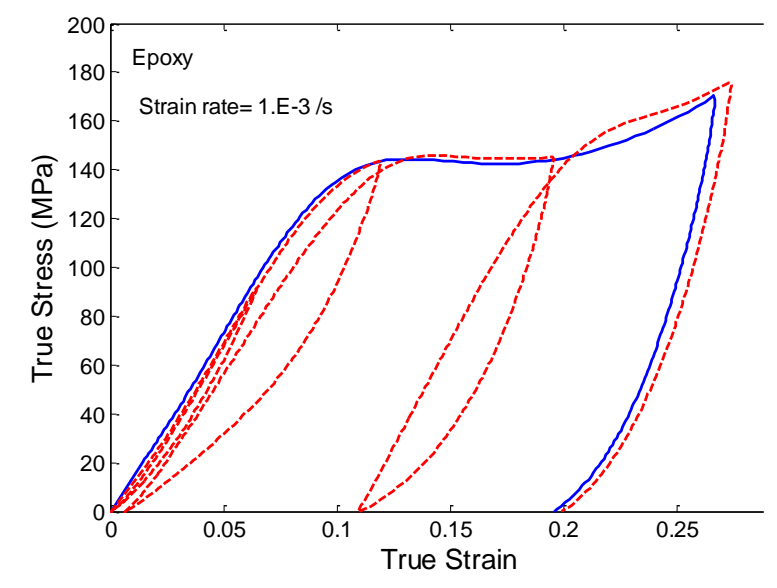

a) Strain rate of $1 . \mathrm{E}-3 / \mathrm{s}$

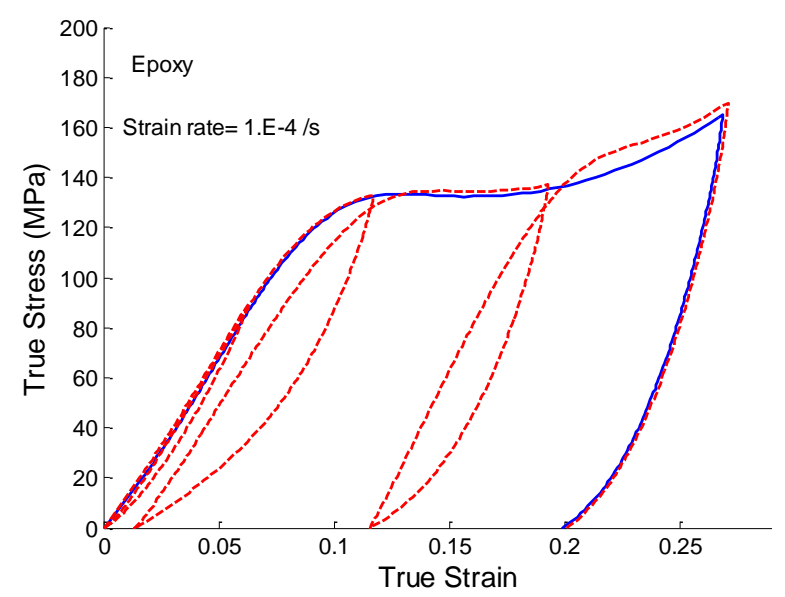

b) Strain rate of $1 . E-4 / \mathrm{s}$

Fig. 5. Comparison of oligo cyclic behavior with loading-unloading behavior of epoxy at two different strain rates. 
As seen in Fig. 5, comparing the behaviors at loading-unloading compression and three repeated cycles loading reveals that loading and unloading behaviors of pure epoxy are almost the same for both case. The main different is only observed in the last cycle. In the oligo cycle case, the stress level is higher than the loading-unloading case. However, it can be concluded that loading history in repeated cycle does not have much effect on the subsequent behavior considering almost the same loading unloading behaviors of epoxy.

\subsubsection{Graphene-epoxy nanocomposite oligo cyclic compression tests}

The oligo cyclic behaviors of graphene-epoxy nanocomposite (0.1 wt \% GNF) are investigated at two strain rates and the results are shown in Fig. 6-8. For a clear view of the behaviors, the stress-strain behaviors of graphene-epoxy ( $0.1 \mathrm{wt} \%$ GNF) at two strain rates are depicted separately in Fig. 6.
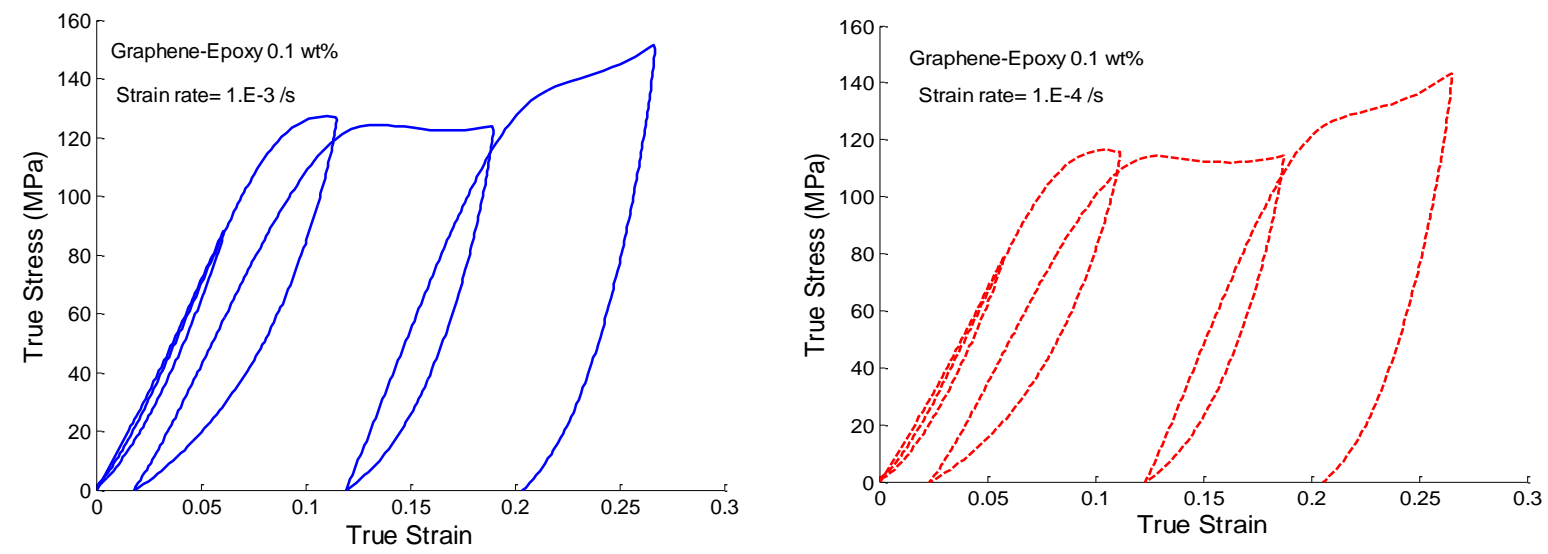

Fig. 6 Cyclic compression behavior of graphene-epoxy nanocomposite $(0.1 \mathrm{wt} \% \mathrm{GNF})$ at two different strain rates.

The following features are observed about graphene-epoxy nanocomposite $(0.1 \mathrm{wt} \%$ GNF): Nonlinearity in the unloading and linearity in the reloading stress-strain curves occur. When the applied stress disappears upon unloading, considerable residual deformation is observed after the first cycle. Since the reloading curve is almost linear and unloading curve is highly nonlinear, a hysteresis loop is conduced. The hysteresis loop decreases with cycle. The behavior is therefore similar to that obtained for epoxy alone. There is a strong difference between loading and unloading, reflecting a change in the deformation mechanisms activated between loading and unloading. 


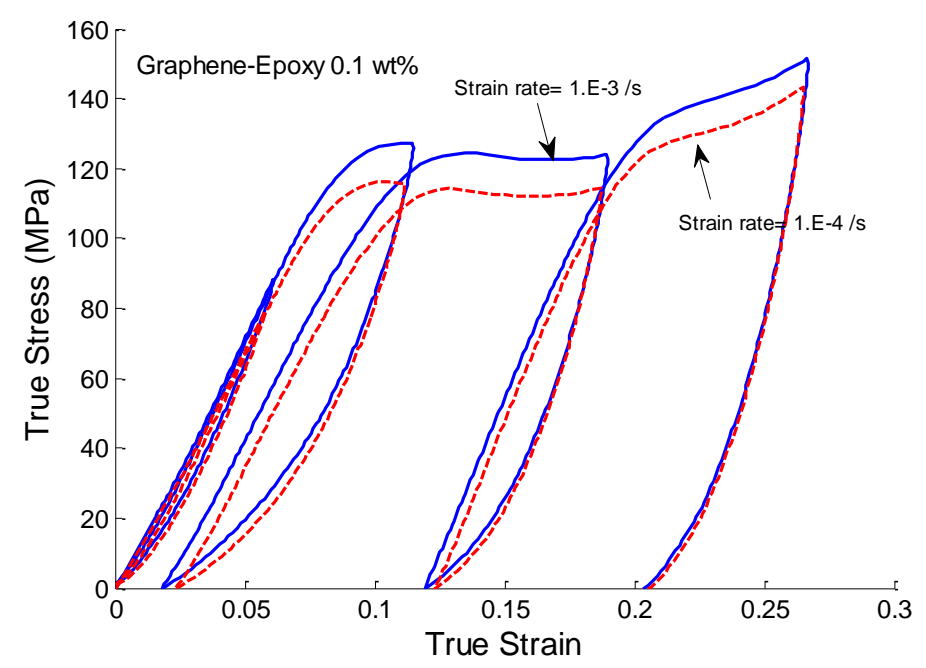

Fig. 7. Rate dependent oligo cyclic behavior of graphene-epoxy nanocomposite $(0.1 \mathrm{wt} \%$ GNF)

Fig. 7 reveals the rate dependent behavior of graphene-epoxy nanocomposite. Viscoplastic deformation during loading is much more prominent compared to unloading behavior. The unloading curves are almost the same in both strain rates.

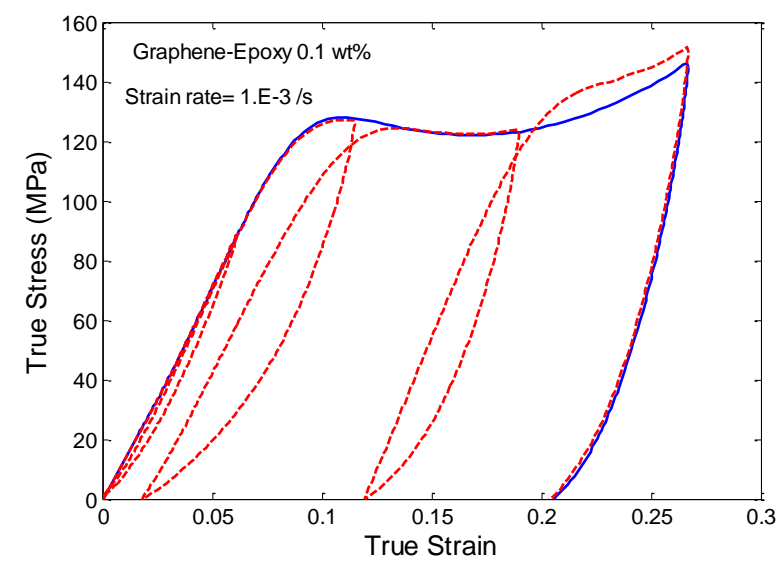

a) Strain rate of $1 . E-3 / \mathrm{s}$

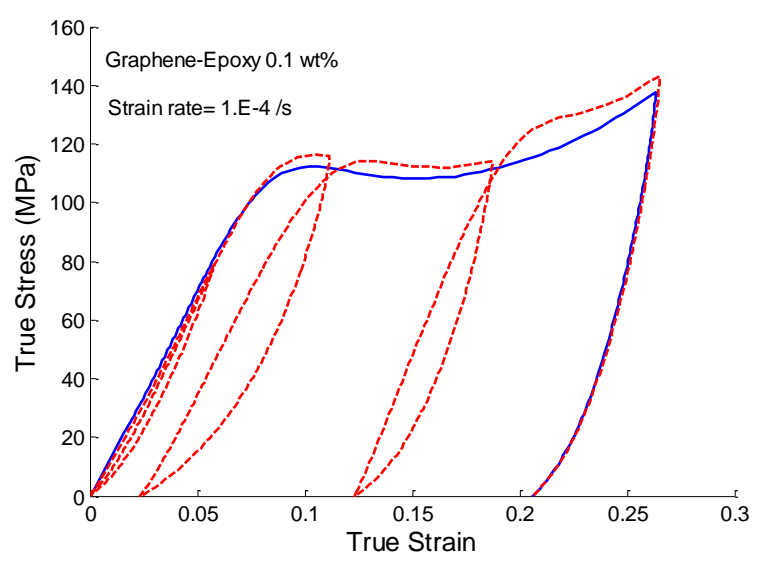

b) Strain rate of $1 . \mathrm{E}-4 / \mathrm{s}$

Fig. 8. Comparison of oligo cyclic behavior with loading-unloading behavior of grapheneepoxy nanocomposite ( $0.1 \mathrm{wt} \% \mathrm{GNF})$ at two different strain rates.

The changes in the elasticity modulus through the cycles are depicted in Table 6. They are determined from reloading stress-strain curves in order to compare the difference between the initial modulus and the subsequent modulus obtained from the difference cycles. It is observed that similar to the behavior of epoxy, decrease in the elasticity modulus, then increase is observed during repeated cycle. 
Table 6. Graphene-Epoxy cyclic compression properties (0.1 wt\% GNF)

\begin{tabular}{|l|l|l|l|l|}
\hline $\begin{array}{l}\text { Strain } \\
\text { rate } \\
(/ \mathrm{s})\end{array}$ & $\begin{array}{l}\text { Elasticity } \\
\text { modulus } \\
(\mathrm{MPa}) \\
\text { Initial loading }\end{array}$ & $\begin{array}{l}\text { Elasticity } \\
\text { modulus }(\mathrm{MPa}) \\
1 . \text { cycle }\end{array}$ & $\begin{array}{l}\text { Elasticity } \\
\text { modulus }(\mathrm{MPa}) \\
2 . \text { cycle }\end{array}$ & $\begin{array}{l}\text { Elasticity } \\
\text { modulus }(\mathrm{MPa}) \\
3 . \text { cycle }\end{array}$ \\
\hline $1 . \mathrm{E}-3$ & $1358 \pm 35$ & $1293 \pm 22$ & $1355 \pm 7$ & $1789 \pm 19$ \\
\hline $1 . \mathrm{E}-4$ & $1345 \pm 59$ & $1278 \pm 33$ & $1357 \pm 10$ & $1796 \pm 6$ \\
\hline
\end{tabular}

\section{Scanning Electron Microscopy (SEM) Fractography}

To obtain more information about the interfacial adhesion between GNF fillers and epoxy matrix, the surfaces of epoxy and graphene-epoxy nanocomposites are investigated by SEM and depicted in Fig. 9 and 10.

To investigate the influences of cyclic deformation on the microstructure, the surfaces of epoxy, graphene-epoxy nanocomposite under compression (loading-unloading) and oligo cyclic compression are investigated by SEM and depicted in Fig. 11, 12.
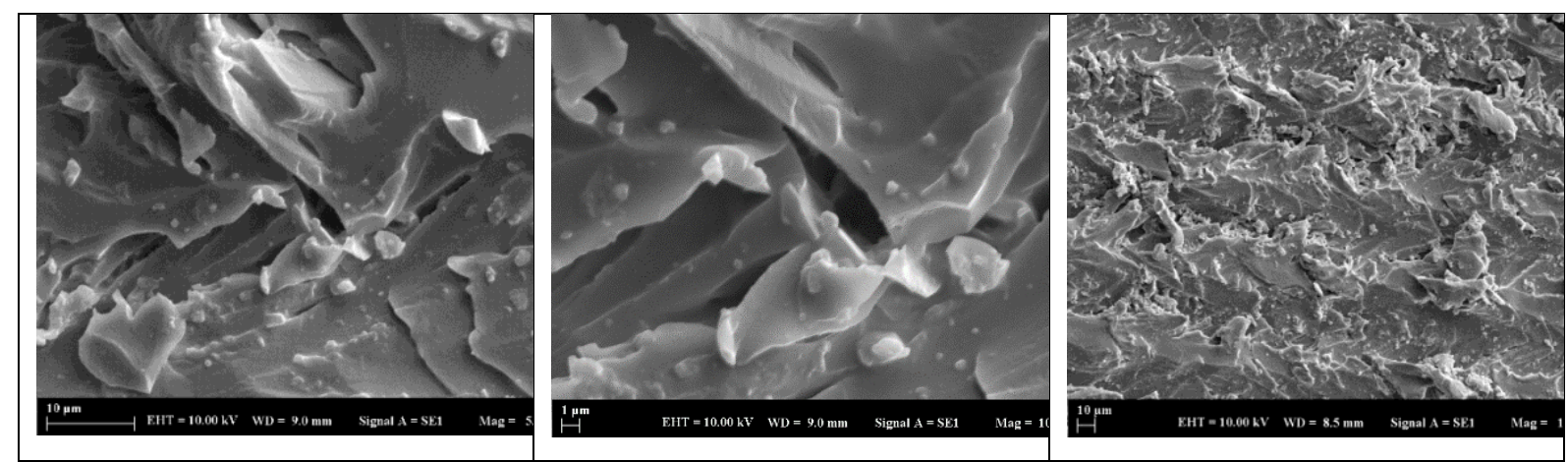

a) Virgin (neat) epoxy
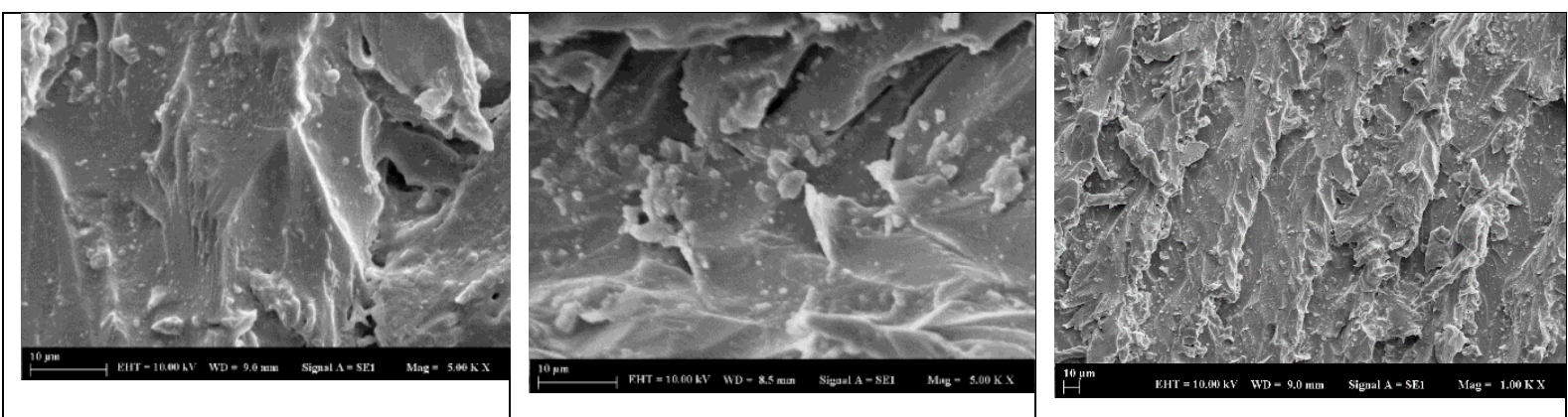

b) Virgin (neat) graphene- epoxy nanocomposite

Fig. 9. SEM micrographs of surfaces of virgin epoxy, virgin graphene- epoxy nanocomposite 

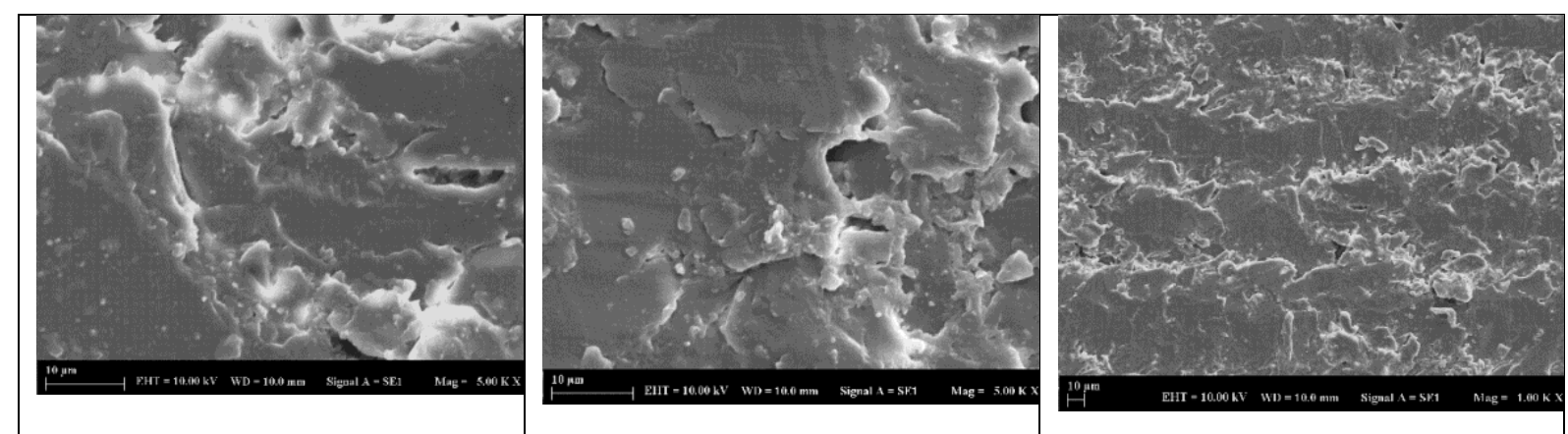

a) Epoxy under compression (loading-unloading)
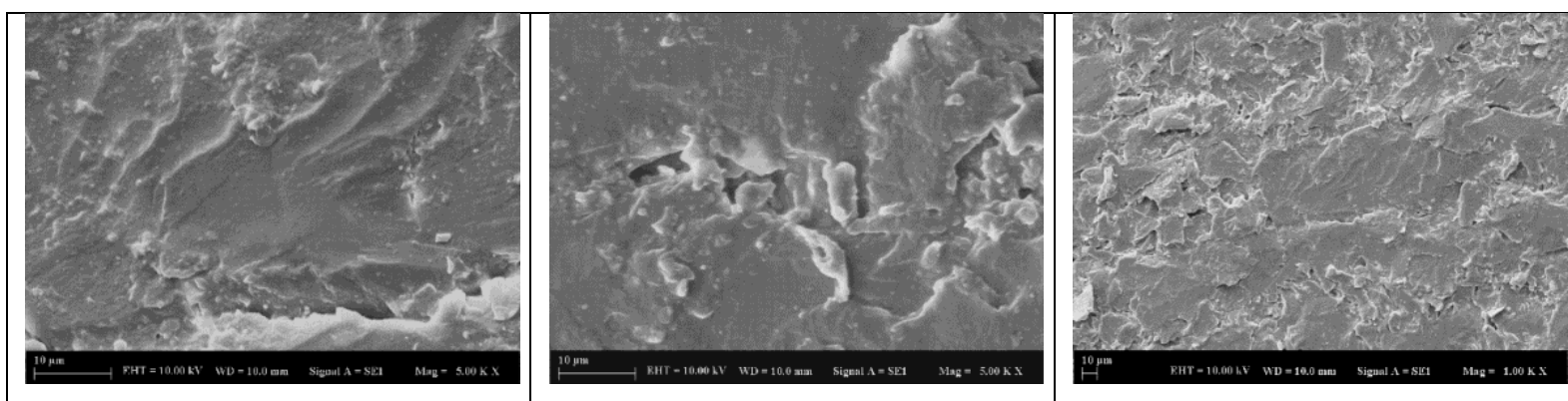

b) Epoxy under oligo cylic compression

Fig. 10. SEM micrographs of surfaces of epoxy under compression loading-unloading and cyclic compression.
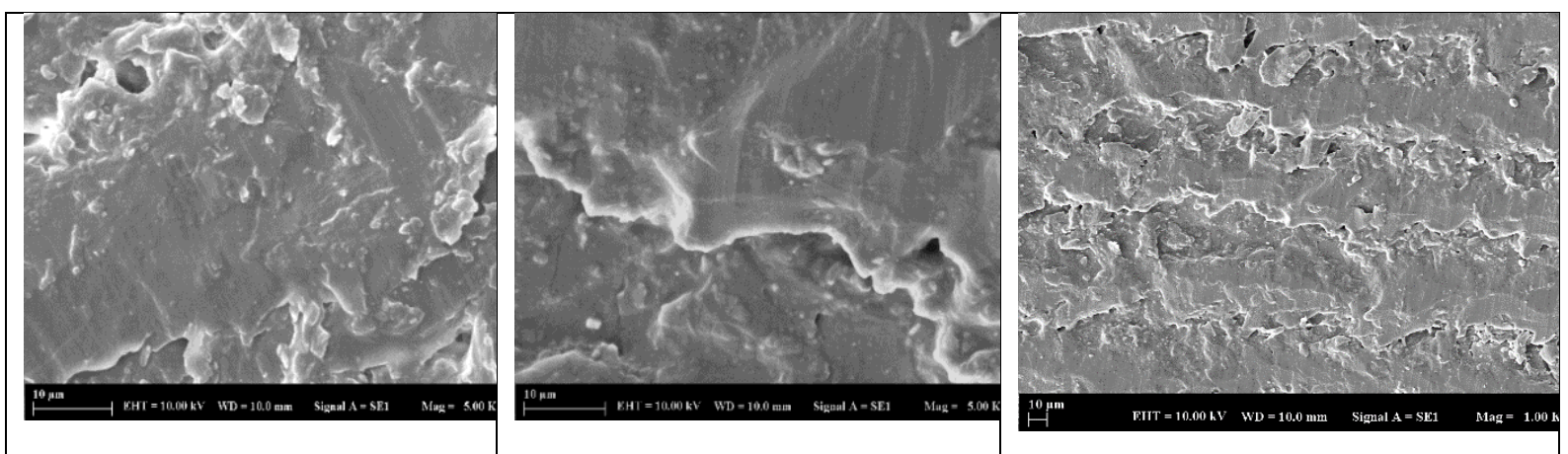

a) Graphene-epoxy (0.1 wt\% GNF) under compression (loading-unloading) 


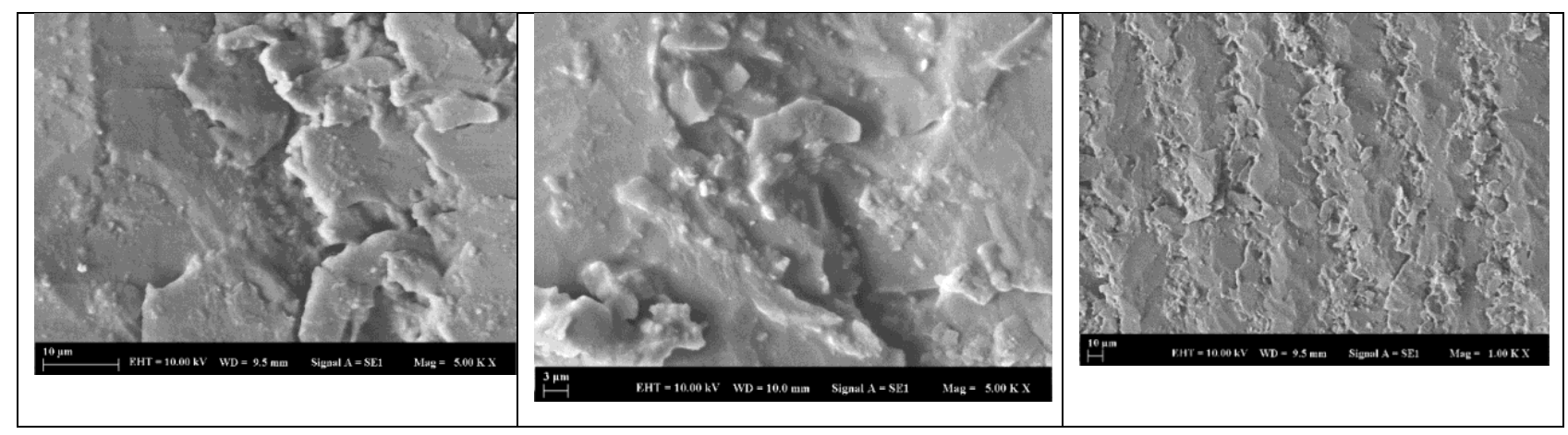

b) Graphene-epoxy (0.1 wt\% GNF) under oligo cylic compression

Fig. 11. SEM micrographs of surfaces of graphene-epoxy (0.1 wt $\%$ GNF) under compression loading-unloading and oligo cyclic compression.

A characteristic surface of a brittle material which is characterized by a clear cleavage of the fracture surfaces is observed for pure epoxy resin. Similar surfaces are obtained when graphene is added. However, when the graphene is present, the micro fragments are also observed. These micro fragments can be attributed to the increase of the brittleness of the matrix by the addition of graphene.

\section{Results and Discussions}

When the behaviors of epoxy and graphene-epoxy during compression loading and unloading are compared (Fig. 3.), it is seen that rate dependency in viscoplastic region is much more prominent in the graphene-epoxy nanocomposite. The strain rate sensitivity is much more prominent at yielding and viscoplastic region. Increasing the strain rate leads to an increase in the stress level. The increase in yield is due to the polymer chain motion as explained above, but this increase is emphasis by the role of fillers in the epoxy. The presence of graphene limits the movements of the chains, which increases the strength. However, compared to epoxy, the yield stresses of graphene-epoxy decrease in both strain rates and a small increase in the elasticity modulus of graphene-epoxy is observed at low strain rate (1.E-4/s). Various factors such as the interfacial adhesion, the aspect ratio, the particle content, the yield stress of the matrix material and the dispersion of particles in the matrix affect the elasticity modulus and the yield stress of the nanocomposites. For each of these effects, a particular configuration is required to optimize the elastic properties of the composite. The dispersion of the GNF in the 
polymer matrix is one of the most crucial factors to be considered. Agglomeration of nanoparticles in polymers induce the local stress concentration, and reduce the particle matrix adhesion, and thus weaken the load transfer efficiency at the interface. The preparation of nanocomposites without agglomeration by the commonly-used solution mechanical mixing techniques is difficult. The tensile strength is highly affected by aggregation of the filler and therefore, it is often found that there is a decrease of the tensile strength as well $[5,7,8]$.

In this work, solution mixing is used as dispersing graphene in epoxy matrix. The main advantages of solution mixing is its simplicity and effectiveness for dispersing nanofillers in the polymer matrix. However, the disadvantages are necessities for sonication for mixing graphene with the polymer and usage of solvent. In the manufacturing process, the procedure given in [10] is considered. However, the compression test results reveal decreases in the yield properties. Among the various parameters of manufacturing, the sonication time is the most important one which can directly affect the dispersion of nanoparticles in the matrix. In the work by Ghaleb et al. [36], the effect of sonication time (10, 20 and $30 \mathrm{~min})$ on the tensile and electrical properties of a GNP-filled epoxy composite is investigated. The effect of sonication time was supported by morphological analysis, which showed an improvement in GNF dispersion with increased sonication time. However, morphological observation performed using SEM showed that the GNF tended to deform and roll up after a long sonication time. The results indicated that the GNP/epoxy composite sonicated for $20 \mathrm{~min}$ showed a slightly improved tensile strength and tensile modulus compared to those sonicated for 10 and $30 \mathrm{~min}$. Seretis et al. [37] have shown that increasing the sonication duration resulted in wrinkling and fracturing of nano platelet. Therefore, considering these works in the literature, it is concluded that the sonication time taken as $1.5 \mathrm{~h}$. as given in Rafiee et al. [10] can be the reason of lower mechanical properties. In the work by Tjong [38], it is stated that long time sonication can induce structural defects and reduce the aspect ratios of graphene, resulting in poorer mechanical strength of resulting nanocomposites.

In the repeated compression cycle of epoxy (Fig.4 and Table 4), with the increasing cycle, the residual strain increases, the slope of linear reloading curve initially decreases, then increases. In the literature, in some of the polymeric materials, steady decline of elastic modulus which indicates a relatively moderate evolution of damage is observed like in the work by Chen et al. [19]. However, in the work by Chen et al. [19], all cycles (loading/unloading) are carried out before reaching the yield stress. In our tests, only one cycle is performed before the yield point. This is the reason why we do not have the same observations. 
Similar to the behavior of epoxy, the comparison of compression loading-unloading behavior with three repeated cycled behavior reveals that visoelastic and unloading behaviors are almost the same in the graphene-epoxy nanocomposite. In the viscoplastic region, the region where hardening starts differs from single loading unloading behavior. Cyclic loading increases the strength around the hardening region. For the strain rate of 1.E-4/s, yielding, softening and hardening strengths are somewhat higher that single loading unloading.

Another important finding is about elasticity modulus change with cycle. The elasticity modulus during oligo cyclic compression loading is calculated from the slope of reloading curve. It is observed that elasticity modulus decreases initially, then it progressively increases with the increase of applied maximum strain. This can be attributed to the fact that initial voids are compressed and deformed. This leads to the decrease in the modulus. At the second cycle, the voids have been crushed leading to an increase in the stiffness, at the next cycle, which takes place in the hardening zone, the modulus continues to increase, since the chains have less free volume to move, which leads to stiffening of the material. Our next work is about modeling of graphene-epoxy nanocomposite with viscoplasticity theory based on overstress for nanocomposites [39]. The change in the elasticity modulus obtained in this work will be used for modeling cyclic behavior of graphene-epoxy nanocomposites.

\section{Conclusions}

The synthesis of graphene is done using electric arc discharge method. Then, the grapheneepoxy nanocomposites are prepared by means of solution mixing. From TEM images, it is seen that the synthesized GNF shows characteristic structure of graphene having different levels of transparency with wrinkles. The number of layers can be also seen from the folded side of graphene flakes. The synthesized GNF has 2 to 10 layers, which is in good agreement with Raman analysis.

Due to the importance of the mechanical characterization of the materials under cyclic loading in the development of damage characterization and fatigue models for polymer composites, [15], loading-unloading compression behavior and repeated cyclic behavior, with a gradually increasing peak stress, of pure epoxy and graphene-epoxy nanocomposites are investigated. For investigation of the viscoelastic and viscoplastic behavior, compression and cyclic tests are performed at two different strain rates (1.E-3/s and 1.E-4/s). By measuring the slope of initial reloading curves, the elastic modulus is calculated. It is observed that compression loading-unloading behavior and oligo cycled behaviors reveal similar visoelastic and unloading behaviors. In the viscoplastic region, the region where hardening starts differs 
from single loading unloading behavior. Cyclic loading increases the strength around the hardening region. For the strain rate of 1.E-4/s, yielding, softening and hardening strengths are somewhat higher that single loading unloading. One of the findings is that loading history in repeated cycle does not have much effect on the subsequent behavior considering almost the same loading unloading behaviors of epoxy and graphene -epoxy nanocomposite. Only in the last cycle somewhat increase in the stress level is observed.

Compared to the mechanical behavior of epoxy, while a small increase in the elasticity modulus in 1.E-4/s strain rate is observed, the yield strength is decreasing with the addition of graphene into epoxy. The decrease in the mechanical properties with the addition of nanofillers is due to the agglomeration of nanofiller. In addition, long time sonication can induce structural defects and reduce the aspect ratios of graphene, resulting in poorer mechanical strength of resulting nanocomposites, [36-38]. As future work, the dispersing method such as three roll milling will be considered to obtain higher mechanical properties.

\section{References}

[1] Novoselov KS (2011) Nobel lecture: graphene: materials in the flatland. Reviews of Modern Physics 83(3): $37-49$.

[2] Suhas DP, Aminabhavi TM, Jeong HH, and Raghu AV (2015) Hydrogen peroxide treated graphene as an effective nanosheet filler for separation application. RSC Advances 5:100984-100995.

[3] Kim KT, Dao TD, Jeong HM, Anjanapura RV, Aminabhavi TM (2015) Graphene coated with alumina and its utilization as a thermal conductivity enhancer for alumina sphere/thermoplastic polyurethane composite. Materials Chemistry and Physics 153:291-300.

[4] Mathew T, Sree RA, Aishwarya S. et al (2020) Graphene-based functional nanomaterials for biomedical and bioanalysis applications. FlatChem 23:1-17.

[5] Papageorgiou DG, Kinloch IA, Young RJ (2017) Mechanical properties of graphene and graphene-based nanocomposites. Progress in Materials Science 90:75-127.

[6] Prolongo M, Salom C, Arribas C, Sánchez-Cabezudo M, Masegosa R, Prolongo S. (2016) Influence of graphene nanoplatelets on curing and mechanical properties of graphene/epoxy nanocomposites. J Therm Anal Calorim 125:629-636.

[7] King JA, Klimek DR, Miskioglu I, Odegard GM (2013) Mechanical properties of graphene nanoplatelet/epoxy composites. J Appl Polym Sci 128 (6):4217-23. 
[8] Wang F, Drzal LT, Qin Y, Huang Z (2015) Mechanical properties and thermal conductivity of graphene nanoplatelet/epoxy composites. J Mater Sci 50 (3):1082-93.

[9] Fu S, Sun Z, Huang P, Li Y, Hu N (2019) Some basic aspects of polymer nanocomposites: A critical review, nano materials science 1: 2-30.

[10] Rafiee MA, Rafiee J, Wang, Z, Song H, Yu ZZ, and Koratkar N (2009) Enhanced Mechanical Properties of Nanocomposites at Low Graphene Content. ACS Nano 3 (12): 3884-3890.

[11] Kuila T, Bose S, Khanra P, Kim NH, Rhee KY and Lee JH (2011) Characterization and properties of in situ emulsion polymerized poly(methyl methacrylate)/graphene nanocomposites. Composites Part A: Applied Science and Manufacturing 42 (11): 1856-1861.

[12] Tang LC, Wan YJ, Yan D et al. (2013) The Effect of Graphene Dispersion on the Mechanical Properties of Graphene/Epoxy Composites. Carbon 60:16-27.

[13] Acar A, Colak O, Uzunsoy D (2015) Synthesis and characterization of graphene-epoxy nanocomposites. Materials Testing 57:(11-12) 1001-1005.

[14] Topal E, Sam Parmak ED, Uzunsoy D, Colak O (2017) Investigation of mechanical properties of graphene and reduced graphene oxide reinforced epoxy matrix composites. Journal of Testing and Evaluation 45: 1182 1191.

[15] Shadlou S, Ahmadi-Moghadam B, Taheri F (2014) The effect of strain-rate on the tensile and compressive behavior of graphene reinforced epoxy/nanocomposites. Materials and Design 59:439-447.

[16] Chhetri S, Adak NC, Samanta P et al. (2017) Functionalized reduced graphene oxide/epoxy composites with enhanced mechanical properties and thermal stability. Polymer Testing 63:1-11.

[17] Zhai Z, Jiang B, Drummer D (2017) Characterization of nonlinear response in quasi-unidirectional E-glass fabric reinforced polypropylene composites under off-axis tensile loading. Polymer Testing 63:521-529.

[18] Wang J, Xiao Y, Kawai M, and Inoue K (2018) Observation and modeling of loading-unloading hysteresis behavior of unidirectional composites in compression. Journal of Reinforced Plastics and Composites 37(5):287-299.

[19] Chen L, Han D, Bai S, Zhao F, and Chen J (2017) Compressive behavior and damage evaluation of a PBX substitute material. Mechanics of Advanced Materials and Structures 24(9):737-744. 
[20] Ayoub G, Zaïri F, Naït-Abdelaziz M. and Gloaguen JM (20109 Modelling large deformation behaviour under loading-unloading of semicrystalline polymers: Application to a high density polyethylene. International Journal of Plasticity 26:329-347.

[21] Cotul U, Parmak EDS, Kaykilarli C, Saray O, Colak O and Uzunsoy D (2018) Development of High Purity, Few-Layer Graphene Synthesis by Electric Arc Discharge Technique. Acta Physica Polonica A 134:289291.

[22] Pimenta MA, Dresselhaus G, Dresselhaus MS et al. (2007) Studying disorder in graphite-based systems by Raman spectroscopy. Phys Chem Chem Phys 9:1276-1291.

[23] Sun DL, Hong RY, Liu JY et al. (2016) Preparation of carbon nanomaterials using two-group arc discharge plasma. Chem Eng J 303:217-230.

[24] Wu Y, Wang B, Ma Y, et al. (2010) Efficient and large-scale synthesis of few-layered graphene using an arcdischarge method and conductivity studies of the resulting films. Nano Research 3: 661-669.

[25] Reina A, Jia X, Ho J et al. (2009) Large Area, Few-Layer Graphene Films on Arbitrary Substrates by Chemical Vapor Deposition, Nano Lett. 9 (1): 30-35.

[26] Paton KR, Varrla E, Backes C et al. (2014) Scalable production of large quantities of defect-free few-layer graphene by shear exfoliation in liquids. Nat Mater 13(6): 624-30.

[27] Meryl D, Sungjin P, Zhu Y et al. (2008) Graphene-Based Ultracapacitors Nano Lett 8 (10) 3498-3502.

[28] Shena B, Ding J, Yan X et al. (2012) Influence of different buffer gases on synthesis of few-layered graphene by arc discharge method. Applied Surface Science 258: 4523-4531.

[29] Bhoyate S, Mensah-Darkwa K, Kahol K, and Gupta R (2018) Advancement in Light Energy Harvesting by using Tailored Graphene in DSSC and BHJ Solar Cells. Current Graphene Science 2:57-78.

[30] Li C, Strachan A (2011) Molecular dynamics predictions of thermal and mechanical properties of thermoset polymer EPON862/DETDA. Polymer 52:2920-2928.

[31] Rana D, Sauvant V and Halary JL (2002) Molecular analysis of yielding in pure and antiplasticized epoxyamine thermosets. J. Mater Sci. 37:5267-5274.

[32] Eyring H (1936) Viscosity, plasticity, and diffusion as examples of absolute reaction rates. J. Chem. Phys. 4:283-291. 
[33] Colak O, Bahlouli N, Uzunsoy D, Francart C (2020) High strain rate behavior of graphene-epoxy nanocomposites. Polymer Testing 81:1-10.

[34] Colak O, Ahzi S, and Remond Y (2013) Cooperative viscoplasticity theory based on the overstress approach for modeling large deformation behavior of amorphous polymers Polymer International 62: 15601565.

[35] Gomez-del Rio T, Rodirguez J, Pearson RA (2014) Compressive properties of nanoparticle modified epoxy resin at different strain rates. Composites: Part B 57:173-179

[36] Ghaleb ZA, Mariatti M, Ariff ZM (2014) Properties of graphene nanopowder and multi-walled carbon nanotube-filled epoxy thin-film nanocomposites for electronic applications: The effect of sonication time and filler loading. Composites: Part A, 58:77-83.

[37] Seretis GV, Theodorakopoulos ID, Manolakos D, Provatidis CG (2018) Effect of sonication on the mechanical response of graphene nanoplatelets/glass fabric/epoxy laminated nanocomposites. Composite Part B Eng. 147: 33-41.

[38] Tjong SC (2013) Synthesis and structural mechanical property characteristics of graphene-polymer nanocomposites, Nanocrystalline Materials, Nanocrystalline materials: their synthesis-structure-property relationships and applications. ed. / Sie Chin Tjong. 2nd ed. London; Waltham, MA : ELSEVIER, 335-375.

[39] Acar A, Colak O, Correia JPM, and Ahzi S (2018) Cooperative-VBO model for polymer/graphene nanocomposites. Mechanics of Materials 125:1-13. 